\title{
Nomadismo e miscigenação no futebol pelotense
}

\author{
Luiz Carlos Rigo ${ }^{2}$
}

Resumo: Tomando como referencia o futebol de Pelotas e Região, este artigo propõe-se a fazer uma reflexão referente ao processo de constituição e consolidação do Futebol Moderno. A partir de fragmentos da memória de antigos "boleiros" da região e de fontes escritas, procuro assinalar como esse futebol, situado em uma Zona Fronteiriça, emergiu, proliferou-se e consolidou-se, estabelecendo relações mútuas, trocas futebolísticas, não só com o futebol europeu e do centro do país (Rio de Janeiro e São Paulo) mas também com o futebol argentino e uruguaio. Palavras Chaves: Futebol, Cultura, Miscigenação.

\section{Apresentação: aportes metodológicos}

Este artigo propõem-se a fazer uma reflexão a respeito dos processos de mestiçagem presentes na trajetória do futebol de Pelotas e Região. Associando fragmentos de oralidades com fontes escritas, procurei mostrar como o futebol da cidade de Pelotas e Região, desde sua emergência, na primeira década do século $\mathrm{XX},{ }^{3}$ manteve forte interação com o futebol europeu, com o futebol do centro do país e como o futebol uruguaio e argentino.

1 O texto que aqui apresento foi elaborado a partir de um item desenvolvido em minha tese de doutorado, Intitulada «Memórias de um Futebol de Fronteira», apresentada junto ao Programa de Pós-Graduação em Educação da Universidade Estadual de Campinas, em 2001. Para a confecção da referida tese, além das fontes escritas e imagéticas, fiz uso de doze depoimentos orais de jogadores, dirigentes e torcedores, vinculados ao futebol da cidade. Para a elaboração desse artigo, considerando o que ele propõe-se, utilizei passagens de quatro desses depoimentos, cujos autores serão apresentados ao longo do texto.

2 Professor Doutor da Escola de educação Física da UFPel.

3 Alguns exemplos que assinalam o lugar de destaque ocupado por Pelotas na historiografia do futebol brasileiro: têm-se registros de partidas demonstrativas de futebol na cidade, em 1901 e 1903, organizadas pelo Sport Club Rio Grande. Em 1904 ocorreu afundação do primeiro clube de futebol, o Athlético Foot-ball Club. Já 1906 é apontado como o ano que assinala a ascensão e consolidação do futebol na cidade, pricipalmente, em decorrência da fundação de três outros clubes (Club Sportivo Internacional, Club Sportivo e Foot-ball Club, que em 1908 se fundem formando E. C. Pelotas). A partir dessas e outras evidências histórica Gilmar Mascarenhas de Jesus ao tratar da história do futebol no Rio Grande do Sul

Movimento Porto Alegre, v.9, n. 3, p.149-161, set./dez. de 2003 
A interação do futebol pelotense com o uruguaio e argentino ganhou maior visibilidade e extrapolou os tradicionais "encontros futebolísticos" a partir dos anos 20 e 30 com a chegada do profissionalismo, formando um estilo próprio, uma espécie de "ethos", que permanece latente nas memórias desse futebol. Em parte, isso foi favorecido por sua localização geográfica, por Pelotas ser uma cidade portuária e fronteiriça, aberta para o "estrangeiro".

\section{O mesmo e o outro: diferença e mestiçagem no futebol moderno ${ }^{4}$}

Nós jogamos com marinheiros de navios e jogamos com diversos navios... OS. C. Rio Grande convidou o Estudiantes. Eles estiveram aqui e depois retribuímos a visita indo à Buenos Aires. Nós convidamos o Vasco da Gama, o Flamengo e o Botafogo para jogarem aqui no Rio Grande e todos vieram?

Jogamos com o Penarol, com o Nacional. O Pelotas jogou lá em Montevidéu, e o Brasil também. Era interessante porque tinha jogadores uruguaios famosos aqui. Este aqui [apontando para a foto] é um, se chamava Pierro, jogou aqui em 45. Tinha um jogador que não aparece na foto, se chamava Palermo, do Penarol,

comenta que, nos anos de 1910, Pelotas "provavelmente seria o terceiro centro futebolístico do país, superado apenas por Rio de Janeiro e São Paulo" (2001, p. 183). Para maiores considerações a respeito da história do futebol em Pelotas, ver: "Memórias de um futebol de fronteira" de Luiz Carlos Rigo; "A bola nas redes e o enredo do lugar: uma geografia do futebol e de seu advento no Rio Grande do Sul" de Gilmar Mascarenhas de Jesus; "O futebol em Pelotas, 1901 - 1941" de Eliseu de Mello Alves.

4 A problemática do "Mesmo" e do "Outro", da diferença, é um dos temas priorizados pelas Ciências Humanas contemporâneas. Entre outros autores que dedicaram atenção ao tema se encontra Michel Foucault. Na introdução do seu livro "As Palavra e as Coisas", reportando-se a outra obra sua, "A história da loucura", ele assinala que "a história da loucura seria a história do Outro - daquilo que, para uma cultura é ao mesmo tempo interior e estranho, a ser portanto excluído (para conjurar-lhe); a história da ordem das coisas seria a história do Mesmo - daquilo que, para uma cultura, é ao mesmo tempo disperso e aparentado, a ser portanto distinguido por marcas e recolhido em identidades." (FOUCAULT Michel. As palavras e as coisas: uma arqueologia das ciências humanas. São Paulo: Martins Fontes, 1987. p.14.) Sobre a diferença infância, velhice, migração, loucura-, ver também: LARROSA, J.; PÉREZ DE LARA N (orgs.). Imagens do Outro, Petrópolis: Vozes, 1998.

5 Entrevista com Seu Dennis Lawson. Descendente de ingleses, seu Dennis nasceu em 1917, é sobrinho de Arthur Ceicin Lawson, que foi fundador e presidente do Sport Club Rio Grande no período de 1908 a 1917. Seu Dennis foi jogador da equipe juvenil do S. C. Rio Grande nos anos 30 e presidente do Clube em 1950, 1951 e 1972. Depoimento coletado na casa do entrevistado, no Balneário Cassino, Rio Grande, RS, em 1996.

Movimento Porto Alegre, v.9, n. 3, p.149-161, set./dez. de 2003 
esse jogador era fabuloso. Ele esteve nesta época aqui. Este outro também é uruguaio. Não me lembro o nome dele. ${ }^{6}$

As duas passagens acima, referentes aos jogos amistosos realizados pelo S. C. Rio Grande e pelo E. C. Pelotas, têm nos intercâmbios e nos entrecruzamentos futebolísticos uma das similitude marcante da gênese do futebol dessas duas cidades (Pelotas e Rio Grande). As partidas acima mencionadas, ocorridas no início do século XX, ilustram um pouco da trajetória híbrida e mestiça de um futebol 'local', que já emergiu fomentado por trocas futebolísticas com o centro do país (Rio de Janeiro e São Paulo), com o futebol europeu, e com o futebol platino, principalmente o argentino e o uruguaio.

As interferências externas sobre o futebol da região se materializavam, principalmente, através das partidas combinadas e das trocas de jogadores, que migravam de um lugar para o outro, levando consigo rastros da cultura e do próprio futebol de onde procediam. Durante as duas primeiras décadas, devido à proximidade geográfica, a influência exercida pelo futebol platino superou a do centro do País. Eliseu de Mello Alves assinala que já em 1910 a cidade de Pelotas presenciou o seu primeiro jogo internacional quando o E. C. Pelotas recebeu a visita da equipe do Estudiantes de Buenos Aires, jogo que acabou com a vitória tranqüila dos argentinos por 7 a $\mathrm{O}^{\top}$ No ano seguinte, o mesmo Pelotas foi novamente o protagonista de outro jogo internacional na cidade. Dessa vez, ele foi o anfitrião do "Scratch" uruguaio. Apesar da vitória um tanto humilhante dos uruguaios por 12 a 0 , o que atesta o estado de desenvolvimento daquele futebol, Eliseu de Mello Alves destaca o significado sociocultural desse acontecimento para a cidade, observando que "o pavilhão, arquibancadas, todos os espaços enfim, ficaram tomados por uma multidão calculada em mais de quatro mil pessoas, a nossa população era de 37 mil habitantes em 1911".

\footnotetext{
6 Entrevista com Seu Virgílio Mozzilo. Torcedor fiel do E. C. Pelotas Virgílio Mozzilo nasceu em 1929, em Pelotas, RS. Foi comentarista esportivo de programas de rádio nos anos 40 e 50 do século passado. A partir de 1951 passou a fazer parte de várias diretorias do E. C. Pelotas. Entrevista realizada no escritório do entrevistado no centro de Pelotas em 1999.

7 ALVES, Eliseu, op. cii, p. 21.

8 Ibid. p. 24. A equipe do Estudiantes, além do E. C. Pelotas enfrentou e venceu o S. C. Rio Grande e o " Scratch" Porto Alegrense. A seleção uruguaia, por sua vez, derrotou o S. C. Rio Grande, o Grêmio F. Portoalegrense e um "Scratch" Gaúcho.
} 
Nos anos que se seguiram, junto com o crescimento do fute-bol da região, presencia-se também um aumento dos jogos envolvendo os times da cidade e os de fora. Além das partidas estaduais e internacionais, cresce também o número de excursões pela região de equipes de renome nacional, prioritariamente do Rio e São Paulo.

Com a proximidade do profissionalismo e com a mutação que se instituiu na natureza das disputas após o inicio dos campeonatos citadinos - Rio Grande, 1912, e Pelotas, 1913 - que acentuavam as rivalidades locais e regionais, os intercâmbios futebolísticos foram acelerados também pelo vai-e-vem, cada vez maior, de jogadores de uma equipe, de uma cidade, ou ainda de um país para outro.

Enquanto o G. S. Brasil ${ }^{9}$ foi pioneiro e referendou sua popularidade agenciando jogadores negros e pobres junto aos times menores da cidade, ainda na década de 20, o E. C. Pelotas, por ser o clube que desfrutava de melhores condições econômicas, singularizou-se por trazer jogadores de fora da cidade. Dentre os estrangeiros, destaca-se a vinda de atletas uruguaios, que na época possuíam grande prestígio no futebol internacional. Sobre a participação deles na história do clube, a revista comemorativa dos seus 90 anos lembra que "o Pelotas, preocupado com o desempenho do time em 1915, trouxe do Rio de Janeiro seus primeiros uruguaios, os irmãos Juan e Augusto Bertone, craques de primeira linha, que jogavam pelo América. Em seguida, veio Norberto Ojeda". Um pouco mais adiante, a mesma revista cita uma lista enorme de nomes e destaca que "El Pancha, por exemplo, formou respeitável zaga com Roberto Stephan, em 1918". ${ }^{10}$

Apesar dos diversos casos anteriores, foi nos anos 30 que essa propensão ao nomadismo intensificou-se dentro do futebol brasileiro. Ganhou visibilidade e conquistou uma determinada legitimidade sociocultural, quando muitos dos nossos craques, na busca de melhores condições profissionais, optaram por sair do País e ir jogar na Europa, principalmente Itália e nos vizinhos Argentina e Uruguai, onde o profissionalismo fora oficializado

\footnotetext{
9 O Grêmio Esportivo Brasil (1911), passou a ser identificado como a equipe mais popular de Pelotas por incluir nos seus plantéis jogadores negros e pobres, construindo com o Esporte Clube Pelotas (1908), naquele momento mais vinculado às elites brancas da cidade, uma rivalidade clássica que até hoje se expressa no tradiconal BRA-PEL

10Revista Esporte Clube Pelotas 90 anos: 1908/1998. p. 16
}

Movimento Porto Alegre, v.9, n. 3, p.149-161, set./dez. de 2003 
em 1931 e 1932, respectivamente. Sobre esse movimento migratório, Waldenyr Caldas especifica que "em 1931, logo após a legalização do futebol argentino, iriam jogar pelo San Lorenzo de Almagro, Petronilho, Vani, Ramón, Teixerinha e Tufy, todos de São Paulo". ${ }^{11}$ O autor prossegue a exemplificação registrando que no ano seguinte iriam para o futebol uruguaio "Congo, Martin, Leônidas da Silva e Domingos da Guia". ${ }^{12}$ Caldas argumenta que essa situação colocava os times brasileiros em uma posição de mero trampolim para as equipes daqueles países, com "uma função idêntica a que têm hoje os times pequenos do interior: revelar bons jogadores para os times grandes da capital".

No contexto interno do nosso futebol, proporcional à implementação da profissionalização, vimos aumentar e proliferar o hábito do jogador mudar de equipe. A adesão, oficial ou não, de vários clubes a posturas profissionalizantes, intensificou as disputas pelos jogadores de maior reconhecimento que permaneciam no País. Paralelo a isso, muitos clubes optavam por garimpar novos craques junto às ligas e times menores, se-duzindo-os com recompensas de dinheiro, trabalho, roupas, etc. Guardadas as diferenças temporais e as devidas particularidades geográficas, isso parece ter sido um traço comum nas práticas do futebol brasileiro dos anos 30 .

Os jogadores, particularmente aqueles com intenções profissionais, começavam a transitar de uma equipe para outra e, muitas vezes, na procura da melhor proposta, eram levados a mudar não só de time, mas também de cidade ou de país. Essa tendência ampliou a diversidade dentro do futebol. As equipes, principalmente as maiores, pouco a pouco foram se tornando um espaço aglutinador de jogadores de diferentes classes sociais, raças e nacionalidades. Menos homogêneos, gradualmente, a maioria dos principais times, deixaram de se caracterizar como um reduto do "Mesmo", tendência que predominou no início do século XX, quando a maioria dos clubes esforçavam-se para constituir times fiéis aos seus respectivos laços socioculturais.

11 CALDAS, Waldenyr, O pontapé Inicial'. Memória do futebol brasileiro (1894-1933).

São Paulo: Ibrasa, p. 203.

12lbid. p. 203. 13lbid. p. 203. 
O futebol jogado na Liga Pelotense, nos anos 30 e 40, apesar de ainda estar regido por um semiprofissionalismo, expressa os indícios desse novo futebol, marcado pela alteridade. Nele, muitos jogadores, não raramente, tornavam-se andarilhos, atletas semiprofissionais que passaram a 'Viver da bola". Rodando por diferentes equipes, eles levavam em suas bagagens as marcas de suas andanças e eram, temporariamente, adotados pelas torcidas dos clubes por onde passavam.

Pela posição estratégica que ocupavam os times de Pelotas absorviam muitos jogadores procedentes das cidades menores, situadas ao seu redor. Enquanto alguns vinham espontaneamente, outros eram requisitados, todos motivados pela expectativa de conseguir um contrato semiprofissional ou um emprego, uma fonte de renda por intermédio do futebol. Foi essa possibilidade que trouxe Seu Alcides de Jaguarão para Pelotas: "Eu tinha 19 anos e tinha vontade de sair de lá. Vim para trabalhar e jogar pelo Bancário. O futebol foi o meio com que eu vim... Trabalhei no Joaquim Oliveira. Era um emprego indireto/ ${ }^{14}$

Apesar de diferentes times da cidade terem em seus quadros jogadores oriundos dos times menores da redondeza, o G. S. Brasil, por ser identificado como o time dos 'negrinhos da estação' e por ter se tornado o clube da cidade de maior popularidade, foi aquele que mais usufruiu dessa estratégia para formar seus planteis, pelo menos até meados dos anos 30.

Além dos jogadores pobres, dos negros e daqueles procedentes de equipes de outras cidades, o futebol da região se sin-gularizou e se diversificou pela afluência de jogadores platinos. Além de confirmada, essa particularidade foi enfatizada em diversos depoimentos que coletei. Facilmente os entrevistados recordavam e citavam uma lista de bons jogadores e técnicos platinos que aqui estiveram, Seu Plácido lembrou que "os clubes de Bagé e de Pelotas tinham uma quantidade enorme de

\footnotetext{
14Entrevista com Seu Alcides de Moraes. Goleiro consagrado da seleção gaúcha de futebol em 1941 e 1942, seu Alcides nasceu em 1916, na cidade de Jaguarão. Em 1936 veio para Pelotas para jogar no Clube Atlético Bancário mas já no ano seguinte, passou a atuar pelo Esporte Clube Pelotas. Durante o depoimento ele comentou que não permaneceu por muito tempo no C. A. Bancário, principalmente porque os dirigentes desse clube não estavam cumprindo o que lhe haviam prometido. Entrevista concedida na casa de um dos filhos de seu Alcides, no centro de Pelotas, em 1999.
} 
jogadores uruguaios e argentinos... Jogadores de seleção", ${ }^{15}$ ressalta, com voz categórica.

Beneficiadas pela localização geográfica e pela significativa posição econômica e cultural que tinham na época, as cidades de Bagé e Santana do Livramento - esta última faz divisa seca com a cidade uruguaia de Rivera - foram elos de conexão do futebol da região com o uruguaio.

Bagé e Livramento eram pólos muito fortes, fortíssimos em futebol. O Guarany de Bagé sempre tinha em sua equipe vários jogadores do Nacional e do Penarol, jogadores fabulosos. O Pelotas mesmo, trouxe de Bagé um jogador que foi irmão de um que foi campeão da copa do mundo de 50 pelo Uruguai. Se chamava Terrera, era de um preço alto, e o Pelotas conseguiu trazer este jogador pra cá! ${ }^{6}$

A característica do futebol moderno, expressa desde o século XIX, de ser uma prática cultural apta a quebrar fronteiras e limites territoriais, aliada à localização geográfica de Pelotas e Rio Grande possibilitou a criação, nessa zona de fronteira, de uma cultura do futebol não circunscrita aos limites nacionais. Alguns futebolistas de Pelotas cultivaram essa curiosidade, essa vontade de acompanhar também o futebol platino.

Eu tinha um irmão que trabalhou e morou na Argentina e ele trazia pra mim a revista o El Gráfico... Foi em 1958, tinha um time na Argentina, o Racing, que foi campeão. Eu olhei assim e vi aqueles jogadores famosos que depois jogaram em vários clubes do Brasil. Eu fixei esse time que até hoje eu não esqueço; tinha o

15 Entrevista com Seu Plácido Nogueira, nascido em 1912, hoje um general da reserva do exército. Foi um assíduo dirigente do Grêmio Atlético Farroupilha e hoje ainda é um torcedor fanático do time. Desde que chegou à Pelotas, em 1933, passou a fazer parte do clube do "militares" na função de Tesoureiro, depois, como ele mesmo conta, "fui de tudo ali. Eu fui presidente por uns 15 anos. A última vez foi em 1960." Entrevista realizada em 1999 no gabinete de trabalho do depoente, no centro de Porto Alegre.

16 Entrevista com Seu Virgílio Mozzilo, 1999. Com o intuito de ilustrar o papel exercido por Santana do Livramento e Bagé no futebol gaúcho. Destaco suas principais conquistas estaduais: três títulos de campeãs (Guarany-BA, em 1920; Grêmio de Bagé, em 1925 e Grêmio Santanense, Santana do Livramento, em 1937); os times dessas duas cidades conquistaram ainda sete vice-campeonatos estaduais (em 1926, 1927, 1928, 1929, 1940, 1944 e 1948). (Revista da Federação Gaúcha de Futebol. Os Melhores Momentos. Edição Comemorativa-1918/1994. 76 anos. Porto Alegre, 1994.). É importante assinalar também que o 14 de Julho FC, de Santana do Livramento, fundado em 14 de julho de 1902, é o segundo clube de futebol mais antigo do Estado. Esta evidência mostra como a emergência do futebol no RS ocorreu quase simultaneamente em duas regiões distintas e distantes (Rio Grande e Santana do Livramento, locais onde respectivamente foram fundados $\circ 1^{Q}$ e $\circ 2^{Q}$ clube de futebol do Estado estão a uma distância aproximada de $400 \mathrm{Km}$ uma da outra). Essa proveniência reforça a tradição não-homogênea do futebol

Movimento Porto Alegre, v.9, n. 3, p.149-161, set./dez. de 2003 
goleiro Garcia, dois zagueiros, Jino Garcia e Garcia Teles, Rastely e Gutierres, Mendes, e Bravo, Simes, Suévis. ${ }^{17}$

O processo migratório que se instituiu no futebol contribuiu para que os principais times da região misturassem jogadores procedentes do próprio clube com os que iniciaram nos times menores de bairros e vilas e outros que vinham de fora da cidade. As equipes de Pelotas, ao mesmo tempo que aproveitavam os jogadores oriundos de times menores da região, também importavam e exportavam jogadores para Porto Alegre, Rio de Janeiro, São Paulo, Uruguai e Argentina. ${ }^{18}$ Após a consolidação do profissionalismo, que na região de Pelotas ocorreu somente em meados dos anos 40 , intensificou-se a saída de craques da região para as equipes maiores. Conhecedores da situação proporcionada pela profissionalização, muitos jogadores migraram em busca de melhores contratos.

Mesmo afastados da cidade, muitos jogadores permaneceram vivos na memória daqueles que compartilharam do início de suas carreiras. Resistindo ao tempo, os jogadores que alcançaram um sucesso maior chegando às grandes equipes do País, tornaram-se ícones na lembrança dos mais antigos e passaram a fazer parte da cultura futebolística da cidade. "O Juvenal, que foi zagueiro do Farroupilha, eu fui pegar ele em Santa Vitória... Depois ele foi pro Vasco, depois foi pro Palmeiras. Foi um

dessas regiões de fronteira. Enquanto em Rio Grande, predominou a influência inglesa e européia, em Santana do Livramento se destacou a influência do futebol uruguaio. No entanto, não muito mais tarde, estas duas vertentes iriam cruzar-se, mesclando suas características.

17 Entrevista com Seu Virgílio Mozzilo, 1999.

$18 \mathrm{~A}$ fim de exemplificar o sentido andarilho do jogador da região e a posição estratégica dos clubes de Pelotas perante às cidades menores da sua volta, mostrarei alguns dados biográficos dos jogadores do G.S. Brasil que foram campeões da cidade no ano de 1946. Gastão Leal iniciou sua carreira no F C. Cerrito, do distrito de Cerrito, em Pelotas; jogou pelo G. A. Farroupilha e G. S. Brasil. Chico, Francisco Carlos de Araújo Silveira, iniciou no G. A. Farroupilha; depois jogou pelo Guarany de Bagé, Fluminense do Rio de Janeiro e G. S. Brasil. Ari Machado dos Santos iniciou jogando pelo S Francisco F C, time do futebol menor da cidade; depois passou para o G. S. Brasil. Tibirica, Alcibiades Brisolára, começou no Marechal Floriano F C, equipe do futebol menor da cidade; depois foi para o G. S. Brasil. Juvenal Amarijo, natural de Santa Vitória do Palmar, iniciou sua carreira no E. C. Vitoriense daquela cidade; depois veio para o G. A. Farroupilha e, mais tarde, passou a jogar pelo G. S. Brasil. Enedino Tavares começou jogando pelo Estrela F C, time do futebol menor do bairro Areai depois foi para o G. S. Brasil. Mortosinha, Darci Lopes da Cunha, começou jogando pelo 15 de Outubro, equipe do futebol menor da cidade; depois passou para o Brasil. Enrique Hernández, natural de Montevidéu, começou jogando pelo Defensor F C daquela cidade; 
zagueirão, foi até da Seleção Brasileira, aquela de 50, que perdeu o campeonato."19

A chegada do negro e do pobre e, um pouco mais tarde, do forasteiro, o jogador profissional andarilho, caracteriza uma nova era no futebol brasileiro. Ele se torna mais híbrido, menos homogêneo e também menos romântico. Apesar desse novo futebol não ser uma exclusividade dessa ou daquela localidade, seu veio transversal de mestiçagem $^{20}$ não exclui as especificidades regionais. ${ }^{21}$

Uma das particularidades que mais chama a atenção nesse futebol de Pelotas e região, ao longo das suas diversas e constantes reconfigurações socioculturais, é a intensidade e a freqüência das interfaces que ele estabeleceu com o futebol platino. Sua situação de fronteira facilitou os contatos intensos com o futebol uruguaio e argentino ao longo de sua trajetória, sobressaindo-se em alguns momentos. $^{22}$

A fregüência do jogos amistosos internacionais e o intercâmbio entre jogadores e técnicos de diferentes países ajuda-

depois teve passagem pelo Peñarol e pelo futebol de Bagé-RS; mais tarde jogou no G. S. Brasil. Tite, Hugo Calandreli, natural de São Paulo, começou jogando pelo Palmeiras, SR Chambao, Osvaldo Rodrigues, também iniciou no futebol menor da cidade, depois jogou pelo E. C. Fiateci e, mais tarde, pelo G. S. Brasil. Galego, Paulo de Souza Lobo, começou a jogar no G. E. Americano, time do futebol menor da cidade, depois ingressou no G. S. Brasil. Scamparini, Irineu Scamparini, natural de São Paulo, começou a jogar no Araras FC, SR O Técnico foi Teté, Francisco José Duarte. (Síntese feita a partir do livro de bolso: Salve GSB Campeões de 1946; Mi meo, 1946.

19 Entrevista com Seu Plácido Nogueira, 1999.

20 O conceito de "mestiçagem" está sendo usado no sentido que lhe atribuiu Mlchel Serres. Maiores considerações sobre esse conceito ver: SERRES, Michel Filosofia Mestiça, Rio de Janeiro: Nova Fronteira, 1993.

21 Para uma síntese sobre as múltiplas influências étnicas e sociais presentes na emergência e na trajetória do futebol brasileiro, consultar o artigo de José Leite Lopes: As raízes mestiças do futebol brasileiro. In: Revista Ciência Hoje. v. 24, n. 139, SBPC.Jun. 1998

22 Eliseu de Mello Alves é um autor que assinala a forte influência do futebol uruguaio sobre o pelotense, destacando como isso ocorreu já na fundação do primeiro time de futebol da cidade em 1904, o Athlético Foot-Ball Club. Nos anos seguintes, os jogos amistosos, a vinda de jogadores e técnicos internacionais deram prosseguimento a esse intercâmbio. Sobre esses amistosos internacionais ocorridos em Pelotas, nas quatro primeiras décadas temos: C. A. Estudiantes. (Buenos Aires, 1910), Artilas de Mello, (cidade de Mello, Uruguai, 1917), "Scratch" argentino. (1918), "Scratch" da cidade de Mello. (Uruguai, 1920), Onward F. C. (Montevidéu, 1924), Wanderes F C. (Montevidéu, 1932), Rampla Juniors. (Montevidéu, 1937), C. A. Urundaí. (Montevidéu, 1938) e C. A. Peñarol. (Montevidéu, 1940). ALVES, Eliseu, op. cit. 1984. Gilmar Mascarenhas de Jesus também faz

Movimento Porto Alegre, v.9, n. 3, p.149-161, set./dez. de 2003 
ram a gestar na região um futebol que mescla, de forma nãoharmônica, códigos culturais e futebolísticos de diferentes épocas e lugares.

\section{A experiência do futebol}

$\mathrm{O}$ veio mestiço e nômade do Futebol Moderno (brasileiro e pelotense), que se fortaleceu agenciando e (re)significando traços culturais de diversas "pátrias futebolísticas", nos revela que a problemática do Outro e do Mesmo não é uma invenção recente e esta presente nas práticas culturais que formam a nossa subjetividade.

Michel Maffessoli, em seu livro "Sobre o Nomadismo", destaca o papel estratégico e singular exercido por andarilhos, "vagabundos", estrangeiros, enfim por todos os "estranhos" nas diversas configurações sócioculturais, desde a Grécia Antiga. Maffesoli procura mostra como eles "servem de intermediários com a exterioridade e, através dela, com diversas formas de alteridade". Nessa perspectiva, prossegue o autor: "eles condicionam as 'relações de reciprocidade', elemento base de qualquer sociabilidade". ${ }^{23}$ Assim, poderíamos dizer que todas as formas de nomadismo foram, e continuam sendo, um condicionante "societal", ${ }^{24}$ principalmente no interior daquelas culturas que expressam uma maior "pulsão migratória". ${ }^{25}$

Por fim, nesse século que começa dando sinais de baixa pluralidade cultural, penso que a experiência do futebol poderia servir com um contraponto a intolerância nacionalista que insistem em tratar os estrangeiros como um concorrente, um inimigo.

O futebol constituiu-se num ícone da cultura por ser mestiço e sem essências fixas, e não por sua pureza. Emblemático do estado de hibridismo cultural atual ele pode nos ajudar a estabelecermos relações de alteridade, e não de discriminação, com

alusão a essa singularidade marcante do futebol da Metade Sul do RS, (Pelotas, Bagé, Santa do Livramento) nas primeiras décadas do século $X X$, destacando que "a predominância dos clubes da Campanha nas primeiras décadas decorre diretamente da influência platina." (2001, p. 160).

23 MAFFESOLI, Michel. Sobre o nomadismo: Vagabundagens pós-modernas. Rio de Janeiro: Editora Record, 2001. p. 45

24 Neologismo criado pelo próprio Maffesoli que aparece ao longo de seu livro anteriormente citado.

25 Iden. p. 51.

Movimento Porto Alegre, v.9, n. 3, p.149-161, set./dez. de 2003 
as diferenças. ${ }^{26}$ Relações "con el otro extranjeiro que permita mantener su potencialidade reflexiva, pero sin reducir lo que esa reflexidade pudeira tener de inquietante para a arrogancia de nuestro discurso, para la seguridad de nuestras práticas y para la solidez de nuestra própria identidade". Porém, essa relação só é possível quando estivermos convencidos que "para (re)conhecer real e radicalmente o outro, é imprescindível desensimesmar-se; isto que dizer, é mister pensar e agir a partir de, com e contra si mesmo".

\section{Uruguaios no E. C. Pelotas}

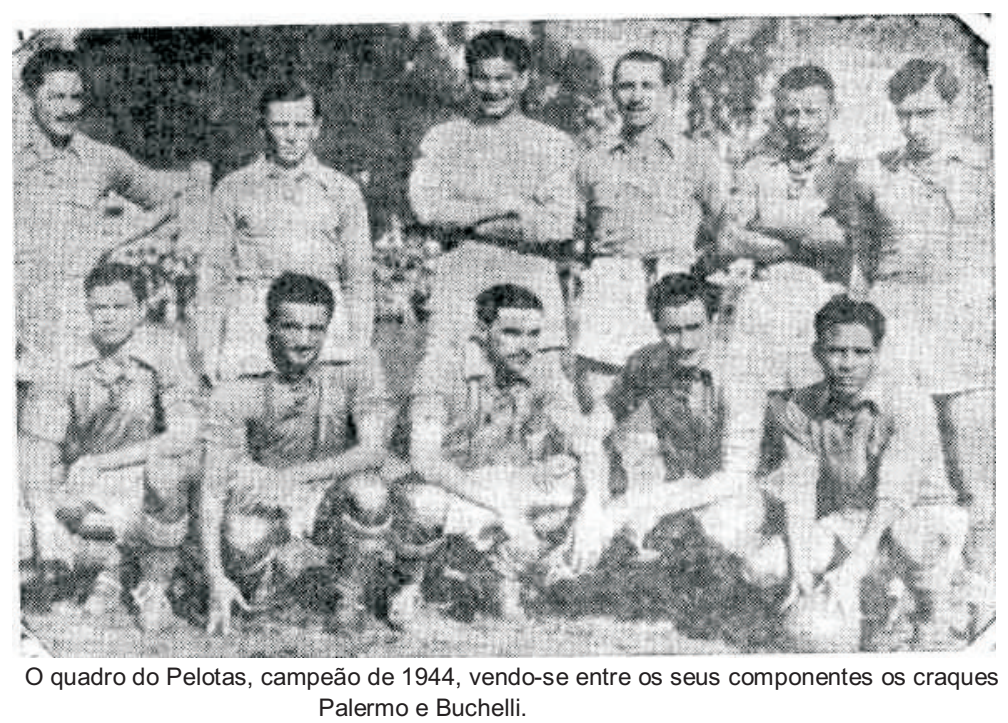

Figura 1. Equipe do Esporte Clube Pelotas de 1944

26 Outras considerações teóricas quanto a problemática da diferença no contexto da cultura moderna ver: SILVA, Tomaz Tadeu da, (org). Identidade e diferença: a pespectiva dos Estudos Culturais. Petrópolis: Vozes, 2000.

27 LARROSA, Jorge. Para Qué Nos Sirven Los Extranjeros?. In: PLACER, E G. \& SANTAMARÍA, E. (Coords.). Contra el Fundamentalismo Escolan Reflexões sobre educación, escolarización y diversidade cultural. Barcelona: Vírus editorial, 1998. p. 53.

28 SANTAMARÍA, Enrique, 1998. p. 64.

Movimento Porto Alegre, v.9, n. 3, p.149-161, set./dez. de 2003 
A foto acima corresponde a equipe do E. C. Pelotas, vencedora do campeonato citadino de 1944. Enquanto fonte histórica imagética ela atua como um registro da presença do futebol uruguaio na cidade, nessa época. $\mathrm{Na}$ fotografia destaca-se a presença de dois atletas uruguaios; Bucheli que veio para o E. C. Pelotas em 1941 e atuou no G. E. Brasil em 1948 e Palermo que veio do Penarol para o Pelotas em 1944. (Fonte: Revista dos Esportes n. 41, 1952, p. 5).

\begin{abstract}
Nomadismo y Micigenación en el Fútbol en la ciudad de Pelotas

Resumén: Tomando como referencia el fútbol de la ciudad de Pelotas y regiones este artículo propone hacer una reflección referente ai proceso de constituición y consolidación del Fútbol Moderno. Apartir de fragmientos de la memória de antiguos "peloteros" de la región y de fuentes escritas, busco apuntar como ese fútbol, ubicado en una Zona de Frontera, emergió, se prolifero y se consolido, estabeleciendo relaciones mutuas, câmbios fútbolisticos, no es solo con el fútbol europeu y del centro de pais (Rio de Janeiro y São Paulo) pero también con el fútbol argentino y uruguayo. Palabras-clave: Fútbol, Cultura, Micigenación.
\end{abstract}

Nomadism and Miscigenation in the soccer from Pelotas
Abstract: This article takes as reference the soccerf rom
Pelotas and region, and is proposed to consider the
constitution and consolidation process of the modem
soccer. Based on written sources and on memories of
former "goalkeepers" from the region, I try to follow how
this soccer, which is in border region, emerged, proliferated
and Consolidated, establishing mutual relations not only to
european soccer and to the soccer from São Paulo and Rio
de Janeiro, which are very important in Brazil, but also to
Uruguayan and Argentinean soccer. Keywords: Soccer,
Culture, Miscigenation.

\section{Referências}

ALVES, Eliseu de Mello. O futebol em Pelotas, 1901 - 1941. Pelotas: Livraria Mundial, 1984.

Movimento Porto Alegre, v.9, n. 3, p.149-161, set./dez. de 2003 
CALDAS, Waldenyr. O pontapé inicial', memória do futebol brasileiro (18941933). São Paulo: Ibrasa, 1990.

FOUCAULT, Michel. As palavras e as coisas: uma arqueologia das ciências humanas. São Paulo: Martins Fontes, 1987.

JESUS, Gilmar Mascarenhas de. A bola nas redes e o enredo do lugar: uma geografia do futebol e de seu advento no Rio Grande do Sul. 2001. 268 f. Tese (Doutorado em Geografia, área Geografia humana ) - Faculdade de Filosofia, Letras e Ciências Humanas, USR São Paulo.

LARROSA, Jorge. Para Qué Nos Sirven Los Extranjeros?. In: PLACER, F. G. \& SANTAMARIA, E. (Coords.). Contra ei Fundamentalismo Escolar, Reflexões sobre educación, escolarización y diversidade cultural. Barcelona: Vírus editorial, 1998. p. 51-71.

LARROSA, J.; PÉREZ DE LARA, N. (orgs.). Imagens do outro. Petrópolis: Vozes, 1998.

LOPES, José Leite. As raízes mestiças do futebol brasileiro. In: Revista Ciência Hoje. v. 24, n. 139, SBPC, Junho 1998. p.18-26.

MAFFESOLI, Michel. Sobre o nomadismo: vagabundagens pós-modernas. Rio de Janeiro: Record, 2001.

RIGO, Luiz Carlos. Memórias de um Futebol de Fronteira. 2001. 247 f. Tese (Doutorado em educação, área sociedade, cultura e educação) — Faculdade de Educação, Unicamp, Campinas.

Revista Esporte Clube Pelotas 90 anos:190S - 1998. Pelotas, 1998.

Revista dos Esportes. Eliseu de Mello Alves e Geraldo Alves (diretores). Tipografia Arauto, n. 41, ano 1952, Pelotas, 1952.

Revista da Federação Gaúcha de Futebol. Os Melhores Momentos. Edição Comemorativa -1918/1994. 76 anos. Porto Alegre, 1994.

Salve GSB Campeões de 1946; Pelotas, (mimeo), (1946).

SANTAMARÍA, Enrique. Do conhecimento de próprios e estranhos (disquisição sociológica). In: LARROSA, J.; PÉREZ DE LARA, N. (orgs.) Imagens do outro. Petrópolis: Vozes, 1998. p.47-66.

SERRES, Michel. Filosofia Mestiça. Rio de Janeiro: Nova Fronteira, 1993.

SILVA, Tomaz Tadeu da, (org.). Identidade e diferença: a perspectiva dos Estudos Culturais. Petrópolis: Vozes, 2000.

Recebido em: 08/09/2003

Aprovado em: 07/10/2003

$$
\begin{array}{r}
\text { Luiz Carlos Rigo } \\
\text { Rua Gonçalves Chaves, } 3063 / 503 \text { - A } \\
\text { Pelotas - RS } \\
96015-560
\end{array}
$$

Icrigo@terra.com.br

Movimento Porto Alegre, v.9, n. 3, p.149-161, set./dez. de 2003 